Calibration of Chemical Kinetic Models Using Simulations of Small-Scale Cookoff Experiments

A. P. Wemhoff, R. C. Becker, A. K. Burnham

March 3, 2008

ASME 2008 Summer Heat Transfer Conference Jacksonville, FL, United States August 10, 2008 through August 14, 2008 
This document was prepared as an account of work sponsored by an agency of the United States government. Neither the United States government nor Lawrence Livermore National Security, LLC, nor any of their employees makes any warranty, expressed or implied, or assumes any legal liability or responsibility for the accuracy, completeness, or usefulness of any information, apparatus, product, or process disclosed, or represents that its use would not infringe privately owned rights. Reference herein to any specific commercial product, process, or service by trade name, trademark, manufacturer, or otherwise does not necessarily constitute or imply its endorsement, recommendation, or favoring by the United States government or Lawrence Livermore National Security, LLC. The views and opinions of authors expressed herein do not necessarily state or reflect those of the United States government or Lawrence Livermore National Security, LLC, and shall not be used for advertising or product endorsement purposes. 


\title{
CALIBRATION OF CHEMICAL KINETIC MODELS USING SIMULATIONS OF SMALL-SCALE COOKOFF EXPERIMENTS
}

\section{HT2008-56108}

\author{
Aaron P. Wemhoff, Richard Becker, Alan K. Burnham \\ Energetic Materials Center \\ Lawrence Livermore National Laboratory \\ Livermore, California 94550 \\ Email: wemhoff2@IInl.gov
}

\begin{abstract}
Establishing safe handling limits for explosives in elevated temperature environments is a difficult problem that often requires extensive simulation. The largest influence on predicting thermal cookoff safety lies in the chemical kinetic model used in these simulations, and these kinetic model reaction sequences often contain multiple steps. Several small-scale cookoff experiments, notably Differential Scanning Calorimetry (DSC), Thermogravimetric Analysis (TGA), One-Dimensional Time-toExplosion (ODTX), and the Scaled Thermal Explosion (STEX) have been performed on various explosives to aid in cookoff behavior determination. Past work has used a single test from this group to create a cookoff model, which does not guarantee agreement with the other experiments. In this study, we update the kinetic parameters of an existing model for the common explosive 2,4,6-Trinitrotoluene (TNT) using DSC and ODTX experimental data at the same time by minimizing a global Figure of Merit based on hydrodynamic simulated data. We then show that the new kinetic model maintains STEX agreement, reduces DSC agreement, and improves ODTX and TGA agreement when compared to the original model. In addition, we describe a means to use implicit hydrodynamic simulations of DSC experiments to develop a reaction model for TNT melting.
\end{abstract}

\section{NOMENCLATURE}

\section{$A^{*}$ Area}

b Body force per unit mass

$c_{v} \quad$ Specific heat at constant volume
$E \quad$ Activation energy

FOM Figure of Merit

$k$ Thermal conductivity

$K_{b} \quad$ Bulk modulus

$n$ Reaction order

n Surface normal vector

$P$ Pressure

$Q \quad$ Heat generation per unit mass

$R \quad$ Ideal gas constant, $8.314 \mathrm{~J} / \mathrm{mol} / \mathrm{K}$

$t$ Time

t Surface traction

$T$ Temperature

$T_{d}$ Decomposition temperature for DSC and TGA

u Displacement vector

$V$ Volume

$w$ Weights in Figure of Merit calculation

$x$ Mass fraction of reactant

$\mathbf{x}$ Independent parameter vector

$Z$ Frequency factor

$\alpha$ Steepest descents algorithm scalar

$\rho$ Density

$\sigma$ Cauchy stress tensor

C Material stiffness

\section{INTRODUCTION}

The proper characterization of the thermal sensitivity of explosives is vital for military and civilian applications, safe handling, and maintenance. The heat release rates for energetic ma- 
terials are temperature dependent. In explosives, when a temperature locally exceeds a certain threshold (i.e. critical temperature), then the energy gained by temperature-dependent heat generation becomes larger than that removed by thermal diffusion. Thermal runaway occurs when heat generation overwhelms thermal diffusion, resulting in rapid local energy gain. This is the ignition mechanism for a thermal explosion, and it is directly linked to the chemical model used to describe an explosive material.

Traditional development of kinetic models use data from a single experiment for calibration, in particular the OneDimensional Time-to-Explosion (ODTX) experiment [1, 2]. These models are then validated using simple models of other cookoff experiments such as the Scaled Thermal Explosion (STEX) experiment [3, 4]. Several examples of this approach are available in literature $[2,5,6,7,8,9]$. Although this approach provides a good basis to calibrate kinetics when none are available, at times the calibrated kinetics do not provide good agreement when applied to smaller-scale cookoff experiments such as Differential Scanning Calorimetry (DSC) or Thermogravimetric Analysis (TGA) [10]. For example, recent work for the explosive HMX has shown large discrepancies in DSC and TGA agreement when the kinetics were calibrated for ODTX data only [11]. A better approach to kinetic data calibration includes these smallscale experiments in the calibration process, and therefore the incorporation of DSC and TGA data is discussed in this paper. Here, we discuss the new calibration methodology and apply it on the explosive 2,4,6-Trinitrotoluene (TNT), which has historically been a commonly used energetic material due to its low melting point, which allows for casting into desired shapes.

\section{THERMAL COOKOFF EXPERIMENTS}

This study updates an existing kinetic model to two cookoff experiments: ODTX and DSC, and then validates the models to two additional experiments: TGA and STEX. Details on these experiments are now provided.

\section{DSC}

DSC experiments apply a fixed temperature ramp (here $\left.10^{\circ} \mathrm{C}\right)$ on a small $(\mathrm{mg})$ sample of explosive, which allows for measurements of heat gain and loss into the pan due to chemical reactions. These experiments may be open to the atmosphere or sealed. Long et al. [12] and LLNL experiments [13] have shown that open-pan DSC doesn't display an exothermic reaction for TNT, but closed-pan experiments at LLNL (Fig. 1 [13]) do provide an exotherm for decomposition at $322.7^{\circ} \mathrm{C}$, which suggests that evaporation in an open pan is faster than decomposition.

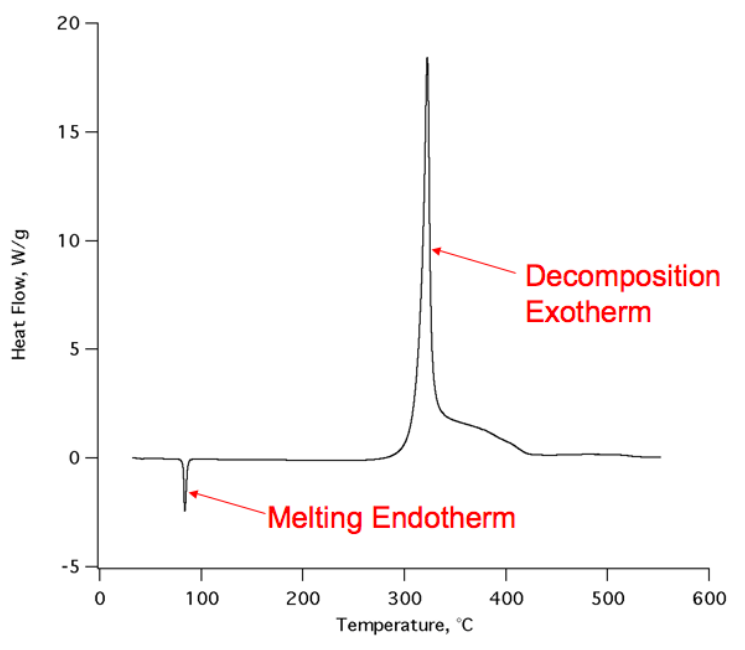

Figure 1. CLOSED-PAN DSC EXPERIMENTAL DATA.

TGA

TGA applies a fixed temperature or ramp rate to a small amount (mg) of explosive for the purposes of measuring mass loss as the sample decomposes. These experiments are performed in an open environment similar to the open-pan DSC. Although $10^{\circ} \mathrm{C} / \mathrm{min}$ ramped TGA experiments of TNT have been performed and show a $50 \%$ mass loss at a surface temperature of $280^{\circ} \mathrm{C}$ [13], the lack of an exotherm in open-pan DSC data suggests that the mass loss observed in TGA is dominated by evaporation. For this reason, we provide predicted decomposition temperatures for TGA in this report but do not include it in the kinetics calibration procedure.

\section{ODTX}

In the ODTX experiment, the explosive is first pressed into a $1 / 2$ " $(1.27 \mathrm{~cm})$-diameter sphere. The outer temperature of the explosive is set to a fixed value by clamping the material into preheated Aluminum anvils. The thermal gradients across the sample relax until ignition. The applied seal to the apparatus holds the material for pressures up to 100-300 MPa. The uncertainty in ODTX experimental data is hard to quantify because the uncertainties lie in the materials processing and apparatus implementation. Reproducibility studies have showed variations in the entire range of data at fixed conditions for ODTX explosion times of $15 \%$ [13]. Here, we choose a range of ODTX temperatures for pure, recrystallized TNT from $210^{\circ} \mathrm{C}$ to $301^{\circ} \mathrm{C}$.

\section{STEX}

In a STEX experiment, the outer surface of a 2 in. $(5.08 \mathrm{~cm})$ diameter $\times 8$ in. $(20.32 \mathrm{~cm})$ long cylinder is heated at a constant temperature ramp rate of $1{ }^{\circ} \mathrm{C} / \mathrm{hr}$ until an explosion occurs. This cylinder is clamped on both ends and contains thin steel side 
walls of chosen thickness to provide a known confining pressure (generally 200-400 MPa). Airgaps are sometimes introduced to allow for examination of intermediate phase transitions [14]. STEX experiments for TNT have shown a surface temperature of $217-223^{\circ} \mathrm{C}$ at explosion [13].

\section{DETERMINATION OF DECOMPOSITION KINETICS}

Brill and James [15] and Long et al. [12] suggest the presence of autocatalysis in the TNT decomposition process. Here, we apply a novel calibration methodology to modify an existing kinetic model that features autocatalysis. In addition, we calibrate a single-step Arrhenius reaction for comparison to isoconversional data by [12].

\section{Existing Kinetic Models.}

Our base kinetic model to be modified is that by McGuire and Tarver [5], which was originally calibrated to ODTX data using the Chemical TOPAZ [16] code. Since their initial study, new information surfaced regarding the presence of impurities in the original samples [2]. Here, it is our intention to modify their original kinetics to match DSC and the updated pure ODTX data as closely as possible. The original kinetics in their notation follow

$$
\begin{gathered}
A \longrightarrow B \\
A+B \longrightarrow 2 C \\
B+B \longrightarrow 2 C
\end{gathered}
$$

where A, B, and C are unreacted liquid TNT, intermediates, and gaseous products, respectively. Melting is ignored in both models since the phase transition occurs at a much lower temperature than decomposition as shown in Fig.1, and therefore the initial state of TNT at the beginning of decomposition is assumed to be liquid. We later showed that the inclusion of melting in the ODTX simulations did not noticeably affect explosion times. These reactions are all of Arrhenius type,

$$
-\frac{d x}{d t}=Z x^{n} \exp \left(-\frac{E}{R T}\right)
$$

where $x, R, T, E$ and $Z$ are the reactant mass fraction, ideal gas constant, temperature, activation energy, and frequency factor respectively. The first reaction is first-order Arrhenius $(n=1)$, the second is first order in $A$ and $B$, and the final reaction is secondorder Arrhenius $(n=2)$. Table 1 provides kinetic parameters for this reaction sequence. In this paper, we refer to this model
Table 1. MCGUIRE-TARVER TNT DECOMPOSITION KINETICS.

\begin{tabular}{lllll}
\hline Reaction & $E, \mathrm{~kJ} / \mathrm{mol}$ & $\ln Z / s^{-1}$ & $Q^{\dagger}, \mathrm{kJ} / \mathrm{kg}$ & $n$ \\
\hline$A \longrightarrow B$ & 184.1 & 35.0 & 125.5 & 1 \\
$A+B \longrightarrow 2 C$ & 144.3 & 26.0 & -3765.6 & 1 \\
$B+B \longrightarrow 2 C$ & 140.2 & 26.2 & -3891.1 & 2 \\
\hline${ }^{\dagger} Q<0$ for exothermic reactions. & & \\
\hline
\end{tabular}

as the McGuire-Tarver model. It should be noted that a nonautocatalytic model was introduced in [2], but it is not applied here.

A second approach to model decomposition applies singlereaction decomposition kinetics to ODTX data for comparison to our updated McGuire-Tarver model. This approach may be applied via a single reaction [17], or by an Arrhenius model with a varying activation energy as a function of reactant mass fraction (the so-called isoconversional method $[12,18,19]$ ). Here, we use methods outlined in $[6,7,8]$ to calibrate a fit to ODTX data using a first-order Arrhenius reaction that follows

$$
A \longrightarrow C
$$

\section{Cookoff computational models.}

The DSC experimental results of Fig. 1 show the heat loss from the material to the pan during decomposition, which is directly related to the change in TNT internal energy. The internal energy incorporates both thermal effects as well as pressurevolume work following the first law of thermodynamics. We here use the implicit hydrodynamics capability of the arbitrary Lagrangian-Eulerian code ALE3D [20] to model changes in TNT internal energy as accurately as possible for DSC simulations. In general, this system contains weak material (defined as the shear modulus being small compared to bulk modulus), especially after gas formation. The only currently feasible way to model such a system implicitly with ALE3D's loosely coupled formulation is to limit the system to a single degree of freedom. Figure 2 shows the two-dimensional, two-zone plane strain piston-cylinder arrangement used to approximate the DSC experiment. The temperatures of all nodes in the system are ramped at a desired rate, and a fixed pressure of 1000 psia $(6.9 \mathrm{MPa})$ is applied on the top of the metal piston. All explosive material exists in a single element in the interior of the piston. The sides and bottom of the piston-cylinder arrangement are constrained in the outward direction. 
The implicit time integration in ALE3D is a standard displacement-based finite element approach using Newton iteration to solve for displacements at the end of each time step. The simulations use the uniform strain hexahedral (3D) or quadrilateral (2D) elements with hourglass control outlined by Flanagan and Belytschko [21]. The momentum equation is written in weak form

$$
\begin{aligned}
P & =\int_{V} \sigma: \delta \mathbf{D} d V-\int_{S} \mathbf{t} \cdot \delta \mathbf{u} d S \\
& -\int_{V} \rho \mathbf{b} \cdot \delta \mathbf{u} d V+\int_{V} \rho \ddot{\mathbf{u}} \cdot \delta \mathbf{u} d V
\end{aligned}
$$

where $\mathrm{P}$ is pressure, $\sigma$ is the Cauchy stress, $\mathbf{t}=\sigma \cdot \mathbf{n}$ is the traction on surfaces with normal $\mathbf{n}, \mathbf{u}$ is the displacement, $\mathbf{b}$ is the body force per unit mass, and $\rho$ is the density. The virtual displacement is $\delta \mathbf{u}$ and $\delta \mathbf{D}=\frac{1}{2}\left[\nabla \delta \mathbf{u}+(\nabla \delta \mathbf{u})^{T}\right]$ is the symmetric part of the virtual displacement gradient. Integration is over volume $V$ with surface $S$. Equation 4 provides the nodal forces used in the equilibrium iterations.

Implementation of the Newton method requires the derivative of the momentum equation with respect to displacements to create the element stiffness matrix.

$$
\begin{aligned}
d P & =\int_{V}[\delta \mathbf{D}: \mathcal{C}: d \mathbf{D}] d V \\
& +\int_{V}\left[(\nabla \delta \mathbf{u})^{T}:(\sigma \cdot(\nabla d \mathbf{u}))\right] d V \\
& +\int_{V}(\sigma: \delta \mathbf{D})(d \mathbf{D}: \mathbf{I}) d V \\
& -\int_{S} \delta \mathbf{u} \cdot\left[\frac{d \mathbf{t}}{d \mathbf{u}}+\mathbf{t} \frac{1}{A^{*}} \frac{d A^{*}}{d \mathbf{u}}\right] \cdot d \mathbf{u} d S \\
& -\int_{V}\left[\rho \delta \mathbf{u} \cdot \frac{d \mathbf{b}}{d \mathbf{u}} \cdot d \mathbf{u}\right] d V \\
& +\int_{V}\left[\rho \delta \mathbf{u} \cdot \frac{d \ddot{\mathbf{u}}}{d \mathbf{u}} \cdot d \mathbf{u}\right] d V
\end{aligned}
$$

The stress and material stiffness, $\mathcal{C}$, are end of step values evaluated using the current estimate of the nodal displacements. Additional terms result from configuration changes over the time step.

The system of equations is solved iteratively for the displacements which satisfy the momentum equations at the end of each time step. For the relatively small systems of equations in this study, a direct solver based on an LU matrix decomposition is used to solve both the hydrodynamic and thermal equations. If the nonlinearity of the momentum equations controls the time

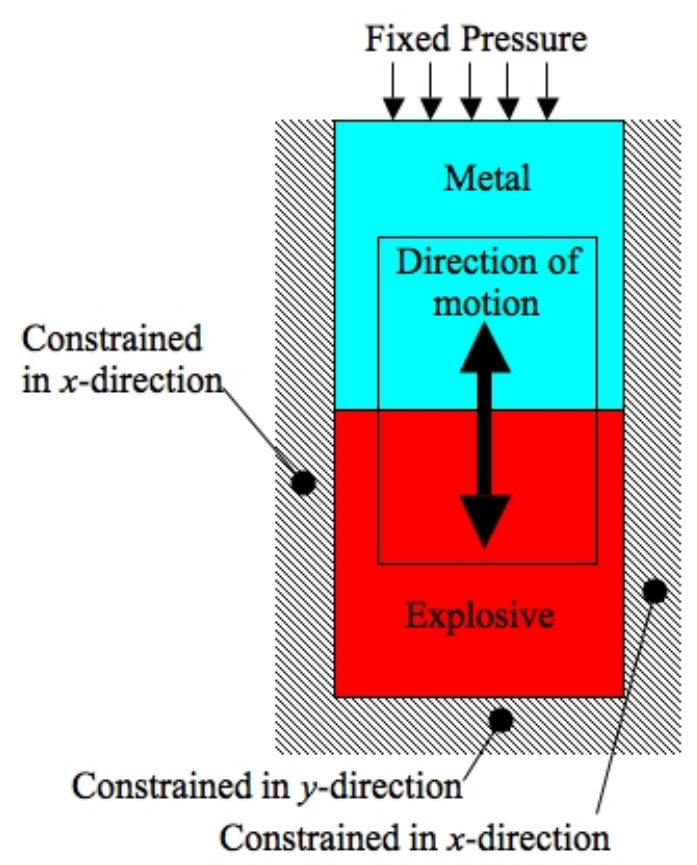

Figure 2. MESH USED IN DSC AND TGA SIMULATIONS.

step, the target number of iterations to reach the convergence tolerances is 3 . Convergence is typically achieved with 1 or 2 iterations if chemistry or the thermal solution are controlling the time step.

The model for TGA was the same as for DSC (see Fig. 2) with the exception that the mesh was constrained throughout, allowing for an explicit simulation with mass scaling. The explicit formulation was required because the implicit hydrodynamics often failed in the isothermal cases due to limitations in the loosely-coupled thermal-hydro algorithm, and use of explicit mechanics greatly reduces required simulation time compared to implicit mechanics. The mass loss was approximated as that calculated by the formation of final gas products in the system (denoted $C$ in Eqns. 1 and 3). We applied the same direct solver for the thermal solution as for the DSC model.

The ODTX computational model is a two-dimensional, axisymmetric quarter-sphere of TNT with diameter 0.5 in. (1.27 $\mathrm{cm})$ corresponding to the experiment. These simulations were performed using explicit hydrodynamics with mass scaling in the same manner as the TGA model. The outer nodes of the sphere are held to the desired fixed temperature for the run. It was assumed that an explosion occurred under one of three conditions: the local HMX temperature rise exceeded $10^{9} \mathrm{~K} / \mathrm{s}$, the maximum zonal temperature exceeded $1000 \mathrm{~K}$, or the amount of gaseous products formed exceeded 5\% of the overall system mass. The latter criterion stems from pressure limitations of the ODTX apparatus and is reflected by TATB simulations by 


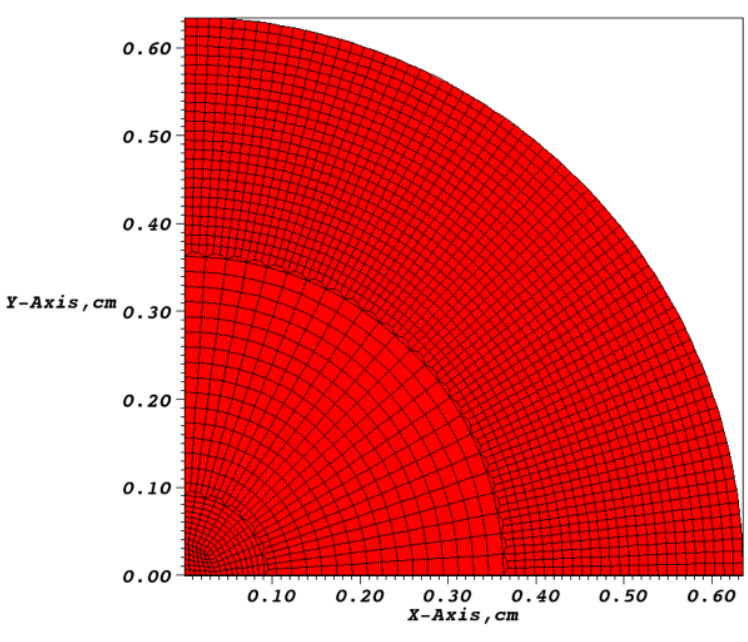

Figure 3. MESH USED IN ODTX SIMULATIONS.

Tarver, Chidester, and Nichols [22]. Figure 3 provides the mesh used in the ODTX simulations. Implicit calculations, where only the outer nodes of the sphere are constrained, were also performed to verify the agreement between implicit and explicit approaches. The thermal and implicit hydrodynamic solutions used a conjugate-gradient sover with a diagonal preconditioner.

Complex mesh geometries for STEX models (e.g. [14]) are generally used for strain prediction, but here we are only concerned with predicting the surface temperature at explosion. Therefore, the mesh used is a simple two-dimensional axisymmetric strip of 50 elements with an aspect ratio of 1.0.

\section{Material properties.}

Values of the temperature-dependent thermal conductivity of the solid and liquid TNT species $\left(A_{\text {solid }}, A-B\right)$, as well as the heat capacity of $A_{\text {solid }}$, are the same as those used by McGuire and Tarver [5], and the properties for the final products $(C)$ were derived using calculations from the thermochemical equilibrium code Cheetah [23] and Bridgmann's thermal conductivity relation for fluids [24]. The solid and liquid TNT densities are provided by [13] and [25]. The density of final products was approximated as being equivalent to the liquid density, which is approximately $10 \%$ lower than the solid density.

Implicit hydrodynamic simulations require definitions of equations of state for each species. Here, we choose a simple polynomial equation of state for the solid and liquid species,

$$
P=P_{0}+K_{b} \mu+\gamma \rho c_{v}\left(T-T_{0}\right)
$$

where $\mu=\left(\rho / \rho_{0}\right)-1, K_{b}$ is the bulk modulus, $\rho$ is the density, $c_{v}$ is the heat capacity at constant volume, and $T$ is temperature.
The parameters $P_{0}$ and $T_{0}$ are ambient pressure and temperature, respectively. The solid TNT bulk modulus and thermal expansion coefficients can be found in [13]. Drimmer [26] provides the liquid TNT volumetric expansion coefficient. Although the exact liquid TNT bulk modulus is unknown, isothermal compressibility data by Pandey et al. [27] for toluene-based liquids provide a bulk modulus near $1 \mathrm{GPa}$, which we use here. We also choose an ideal gas form for the final products,

$$
P=(\gamma-1) \rho c_{v} T
$$

where $\gamma$ was determined using Cheetah [23]. Table 2 gives material properties for the various components.

\section{Calibration methodology.}

The general approach used here was to build the reaction network in stages by approximating the presence of certain reactions for a given experiment. The optimization in each stage was based on the minimization of an overall Figure of Merit (FOM) calculated by comparing modeled and experimental results. In general, the FOM is calculated as

$$
F O M=\sum_{i=1}^{N_{D S C}}\left(w_{D S C} F_{D S C}\right)_{i}^{2}+\sum_{i=1}^{N_{O D T X}}\left(w_{O D T X} F_{O D T X}\right)_{i}^{2}
$$

where the number of DSC and ODTX experiments is $N_{D S C}$ and $N_{\text {ODTX }}$, respectively. The value of $F_{i}$ is the percentage error and assigned weight of model run $i$ when compared to the corresponding experimental data, and $w$ values are assigned weights.

Calibration was performed by applying a steepest descents/1-d bisection algorithm applied as a wrapper script over ALE3D simulations of the model experiments. For a series of samples, the gradient of the FOM was first determined to determine the direction of steepest descent, and then a series of 15 bisections was used to determine the minimum FOM along the steepest descent line segment between $\mathbf{x}_{\mathbf{s t a r t}}$ and $\mathbf{x}_{\mathbf{m a x}}$, where

$$
\mathbf{x}_{\text {max }}=\mathbf{x}_{\text {start }}+\alpha_{\text {max }} \nabla(F O M)
$$

where $\alpha_{\max }$ is either 1.0 or smaller depending on the size of the allowable ranges of independent parameters $\mathbf{x}$. Data were available for a single DSC experiment, and 8 ODTX experimental data points were chosen for calibration. The values of $w_{D S C}$ and $w_{O D T X}$, were chosen to be 8 and 1 , respectively to allow for equal contributions from each set of experiments to the overall FOM. The activation energies, reaction orders, and heats of reaction 
Table 2. TNT MATERIAL PROPERTIES.

\begin{tabular}{|c|c|c|c|}
\hline Species & $A_{\text {solid }}$ & {$[A, B]$} & $C$ \\
\hline$\rho, \mathrm{kg} / \mathrm{m}^{3}$ & 1.654 & 1.459 & 1.459 \\
\hline$K_{b}, \mathrm{GPa}$ & 6.5 & 1.0 & N/A \\
\hline$\gamma$ & 0.7347 & 0.5489 & 1.196 \\
\hline Temperature, $\mathrm{K}$ & $c_{v, A_{\text {solid }}}$ & $c_{v,[A, B]}$ & $c_{v, C}$ \\
\hline 273 & 1.05 & 1.36 & 0.9835 \\
\hline 293 & 1.13 & 1.36 & 1.015 \\
\hline 433 & 1.67 & 1.36 & 1.239 \\
\hline 673 & 2.59 & 1.36 & 1.624 \\
\hline 1073 & 3.86 & 1.36 & 3.308 \\
\hline 1473 & 3.86 & 1.36 & 3.313 \\
\hline 1873 & 3.86 & 1.36 & 1.941 \\
\hline 2273 & 3.86 & 1.36 & 2.080 \\
\hline Temperature, K & $k_{A_{\text {solid }}}$ & $k_{[A, B]}$ & $k_{C}$ \\
\hline 273 & 0.262 & 0.262 & 0.272 \\
\hline 293 & 0.259 & 0.259 & 0.263 \\
\hline 433 & 0.238 & 0.238 & 0.201 \\
\hline 673 & 0.202 & 0.202 & 0.0952 \\
\hline 1073 & 0.153 & 0.153 & 0.0814 \\
\hline 1473 & 0.153 & 0.153 & 0.0885 \\
\hline 1873 & 0.153 & 0.153 & 0.0893 \\
\hline 2273 & 0.153 & 0.153 & 0.0861 \\
\hline
\end{tabular}

from the McGuire-Tarver model (Eqn. 1) were preserved, but the frequency factors were adjusted.

A single-step first-order Arrhenius model (Eqn. 3) was also calibrated using the two data points approach outlined in $[6,7$, 8] for ODTX temperatures at $210^{\circ} \mathrm{C}$ and $301^{\circ} \mathrm{C}$. The calibrated parameters for this model are $E=129.1 \mathrm{~kJ} / \mathrm{mol}$ and $\ln Z / \mathrm{s}^{-1}=$ 21.16. Note that this activation energy is similar to the value of $140 \mathrm{~kJ} / \mathrm{mol}$ stated for the isoconversional approach [12].

\section{Results.}

The calibration procedure was run for 15 samples, which corresponded to approximately 110 hours of running time. Table 3 provides the calibrated kinetic parameters for the updated
Table 3. UPDATED MCGUIRE-TARVER MODEL.

\begin{tabular}{llll}
\hline Reaction & $E, \mathrm{~kJ} / \mathrm{mol}$ & $\ln Z / s^{-1}$ & $n$ \\
\hline$A \longrightarrow B$ & 184.1 & 36.21 & 1 \\
$A+B \longrightarrow 2 C$ & 144.3 & 21.95 & 1 \\
$B+B \longrightarrow 2 C$ & 140.2 & 27.82 & 2 \\
\hline
\end{tabular}

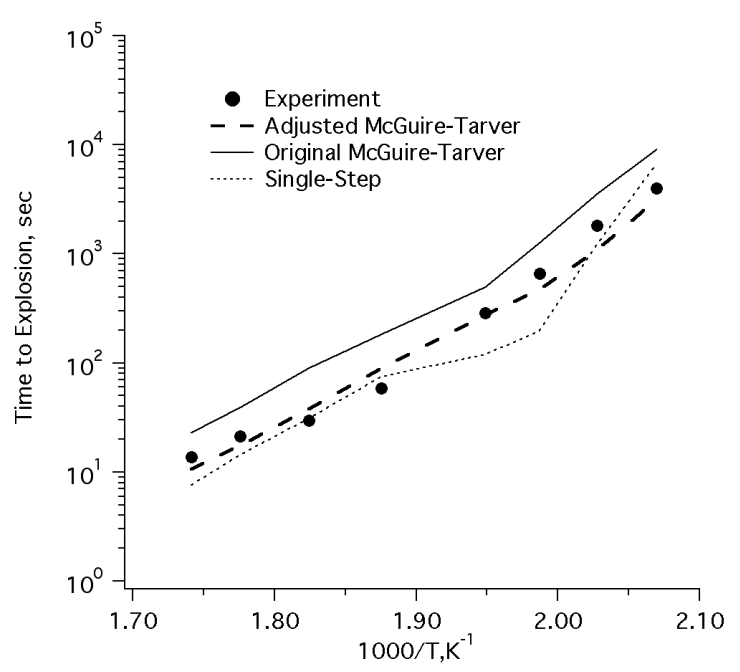

Figure 4. COMPARISON OF EXPERIMENTAL AND SIMULATED ODTX DATA.

McGuire-Tarver model. Figure 4 provides comparisons in experimental and predicted ODTX explosion times for the updated McGuire-Tarver, original McGuire-Tarver, and one-step Arrhenius kinetic models, which correspond to errors of $27 \%, 119 \%$, and $32 \%$ when compared to experiment. Predicted DSC surface temperatures at peak heat release are $278^{\circ} \mathrm{C}, 295^{\circ} \mathrm{C}$, and $344^{\circ} \mathrm{C}$ for the updated McGuire-Tarver, original McGuire-Tarver, and single-step Arrhenius models, respectively, which corresponds to an error of $13.9 \%, 8.6 \%$, and $6.6 \%$ when compared to the experimental value of $322.7^{\circ} \mathrm{C}$. Therefore, the single-reaction model appears to provide the best agreement among the three models used in this study.

Validation runs were performed for these values to predict STEX surface temperatures at explosion and TGA 50\% mass loss. Predicted STEX surface temperatures at explosion are $182^{\circ} \mathrm{C}, 191^{\circ} \mathrm{C}$, and $195^{\circ} \mathrm{C}$ for the updated McGuire-Tarver, original McGuire-Tarver, and single-step Arrhenius models, respectively, which corresponds to an error of $17.3 \%, 13.2 \%$, and $11.4 \%$ when compared to the experimental value of $220^{\circ} \mathrm{C}$. The under-prediction of STEX surface temperatures at explosion may be due to liquid TNT convection in the STEX vessel, and more 
investigation is needed. Predicted TGA surface temperatures at $50 \%$ mass loss surface temperatures at explosion are $278.9^{\circ} \mathrm{C}$, $296.7^{\circ} \mathrm{C}$, and $348^{\circ} \mathrm{C}$ for the updated McGuire-Tarver, original McGuire-Tarver, and single-step Arrhenius models, respectively, which corresponds to an error of $0.4 \%, 6.0 \%$, and $24.3 \%$ when compared to the experimental value of $280^{\circ} \mathrm{C}$. These TGA results help validate our calibrated McGuire-Tarver kinetics when compared to the other two models, but caution must be used in interpreting these results since open-pan DSC and TGA data show a strong influence by evaporation.

\section{DETERMINATION OF MELTING KINETICS}

Phase change can be incorporated into thermal codes in a variety of ways (see [28]), such as a spike in heat capacity [29], the addition of heat absorption based on the latent heat and change in quality [30], nodal temperature adjustment until the latent heat has been satisfied [31], or through solution of the enthalpy [32]. Here, we provide a means to describe phase change as a firstorder Arrhenius reaction,

$$
A_{\text {solid }} \longrightarrow A
$$

We apply melting as a first-order phase transition following [33]. The melting point of TNT is generally accepted as being close to $81^{\circ} \mathrm{C}[2,25]$. A latent heat of $93.3 \mathrm{~J} / \mathrm{g}$ was used $[2,5]$.

Figure 5 provides the melting endotherm from the DSC experiment. Computational models of the DSC experiment were performed to calibrate the activation energy and frequency factor for the kinetic reaction in Eqn. 10. Manual iteration was used to calibrate kinetic parameters of $836.8 \mathrm{~kJ} / \mathrm{mol}$ and 278.8 for $E_{\text {melt }}$ and $\ln Z_{\text {melt }} / s^{-1}$, respectively. The difference in spike magnitude in Fig. 5 is due to approximations in the computational model as well as additional heat loss mechanisms in the DSC experiment. These kinetic parameters should not be interpreted literally. They are a computational convenience in which the very high activation energy maintains the melting transition at approximately the same temperature for different heating schedules.

\section{CONCLUSIONS}

We here provide a simple yet effective means to calibrate a kinetic model to multiple small-scale experiments. The use of multiple experiments often gives insight into the behavior of energetic materials that is not apparent from a single experiment, such as the determination of the excess formation of product gases early in the decomposition process for HMX [11]. Here, we find that errors in the original experimental data, as well as advances in predictions of material thermal properties are easily

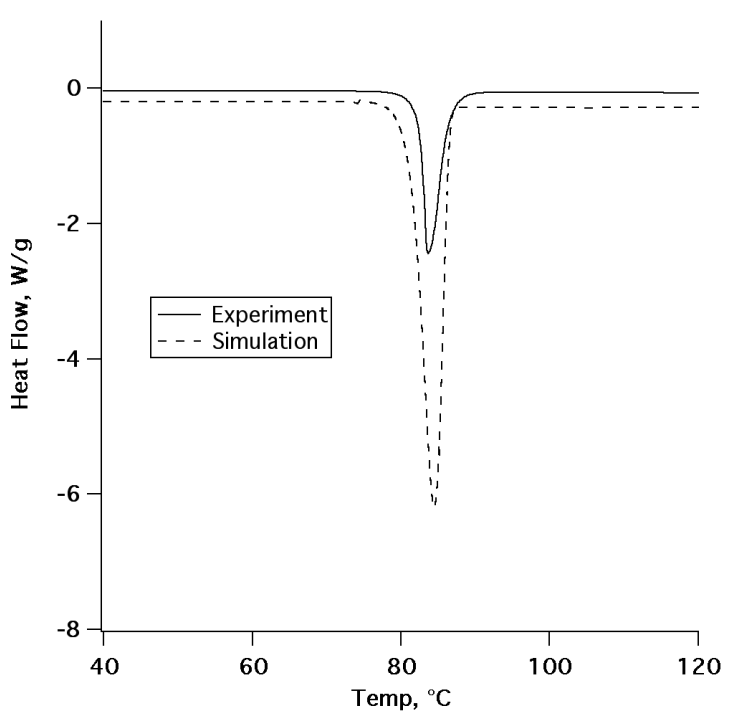

Figure 5. EXPERIMENTAL AND SIMULATED DSC MELTING ENDOTHERM.

updated when a steepest-descents/1d-bisection algoritm is applied. Updating the McGuire-Tarver model provides improved ODTX and TGA agreement while sacrificing DSC agreement, yet the STEX agreement remains unchanged. Our single-step reaction model, while exhibiting reasonable agreement to ODTX and TGA experimental data, does not provide a good prediction to TGA and STEX explosion times. All of these results show that agreement with one type of cookoff experiment does not necessarily correspond to good agreement with others.

\section{ACKNOWLEDGMENT}

Retrieval of DSC data by Michaele Kashgarian and discussions with Craig Tarver are gratefully acknowledged. This work performed under the auspices of the U.S. Department of Energy by Lawrence Livermore National Laboratory under Contract DEAC52-07NA27344.

\section{REFERENCES}

[1] Catalano, E., McGuire, R., Lee, E., Wrenn, E., Ornellas, D., and Walton, J., 1976. "The Thermal Decomposition and Reaction of Confined Explosives". In Proceedings of Sixth Symposium (International) on Detonation.

[2] Tran, T., Simpson, L., Maienschein, J., and Tarver, C., 2001. "Thermal Decomposition of Trinitrotoluene (TNT) with a New One-Dimensional Time to Explosion (ODTX) Apparatus". In Proceedings of 32nd International Annual Conference of Fraunhofer-Institut fur Chemische Technologie (ICT). 
[3] Wardell, J. F., and Maienschein, J. L., 2002. "The Scaled Thermal Explosion Experiment". In Proceedings of the Twelfth International Symposium on Detonation.

[4] Maienschein, J. L., DeHaven, M. R., Sykora, G. B., Black, C. K., Wardell, J. F., McClelland, M. A., Strand, O. T., Whitworth, T. L., and Martinez, C., 2006. "Thermal Explosion Violence for Several Explosives - Measurements and Interpretation". In Proceedings of the Thirteenth International Symposium on Detonation.

[5] McGuire, R., and Tarver, C., 1981. "Chemical Decomposition Models for the Thermal Explosion of Confined HMX, TATB, RDX, and TNT Explosives". In Proceedings of Seventh Symposium (International) on Detonation.

[6] Wemhoff, A. P., Burnham, A. K., and Nichols III, A. L., 2007. "The Application of Global Kinetic Models to HMX Beta-Delta Transition and Cookoff Processes". J. Phys. Chem. A, 111(9), pp. 1575-1584.

[7] Wemhoff, A. P., Burnham, A. K., Nichols III, A. L., and Knap, J., 2007. "Calibration Methods for the Extended Prout-Tompkins Chemical Kinetics Model and Derived Cookoff Parameters for RDX, HMX, LX-10 and PBXN-109". In Proceedings of 2007 ASME-JSME Thermal Engineering Summer Heat Transfer Conference. Paper HT2007-32279.

[8] Wemhoff, A. P., Burnham, A. K., and Maienschein, J. L., 2006. "Global Kinetic Models of AP/Al-based Propellants". In Proceedings of 2006 JANNAF Meeting.

[9] Tarver, C. M., and Tran, T. D., 2004. "Thermal Decomposition Models for HMX-Based Plastic Bonded Explosives". Comb. Flame, 137, pp. 50-62.

[10] Burnham, A. K., and Weese, R. K., 2004. Thermal Decomposition Kinetics of HMX. Tech. rep., Lawrence Livermore National Laboratory, Livermore, CA, November. Report UCRL-TR-204262 Rev. 1.

[11] Wemhoff, A. P., Knap, J., Howard, W. M., Burnham, A. K., and Nichols III, A. L., 2008. An HMX Kinetic Model Calibrated Using Simulations of Multiple Small-Scale Thermal Safety Tests. Submitted to J. Phys. Chem. A, March.

[12] Long, G. T., Brems, B. A., and Wight, C. A., 2002. "Autocatalytic Thermal Decomposition kinetics of TNT". Thermochimica Acta, 388(1), pp. 175-181.

[13] Owens, C., 2007. LLNL Explosives Reference Guide. Tech. rep., Lawrence Livermore National Laboratory, Livermore, CA, October. Report UCRL-WEB-236503.

[14] Knap, J. in preparation.

[15] Brill, T. B., and James, K. J., 1993. "Thermal Decomposition of Energetic Materials. 62. Reconciliation of the Kinetics and Mechanisms of TNT on the Time Scale from Microseconds to Hours". J. Phys. Chem., 97(34), pp. 87598763.

[16] Nichols III, A. L., and Westerberg, K. W., 1993. "Modification of a Thermal Transport Code to Include Chemistry with Thermally Controlled Kinetics". Numer. Heat Trans. $B, \mathbf{2 4}(4)$, pp. 489-509.

[17] Erikson, W. W., 2005. "Application of Global Decomposition Models to Energetic Material Cookoff". In Proceedings of JANNAF 40th CS, 28th APS, and 4th MSS Joing Meeting.

[18] Friedman, H. L., 1964. "Kinetics of Thermal Degradation of Char-Forming Plastics from Thermogravimetry. Application to Phenolic Plastic.”. J. Poly. Sci. C., 6, p. 183.

[19] Flynn, J. H., 1996. "Early Papers by Takeo Ozawa and their Continuing Relevance". Thermochim. Acta, 283, pp. 3542.

[20] Nichols III, A. L., 2007. Users Manual for ALE 3D - An Arbitrary Lagrange/Eulerian 3D Code System. Tech. rep., Lawrence Livermore National Laboratory, Livermore, CA, May. UCRL-MA-152204 Rev 6.

[21] Flanagan, D. P., and Belytschko, T., 1981. "A Uniform Strain Hexahedron and Quadrilateral with Orthogonal Hourglass Control”. Int. J. Num. Meth. Eng., 17(5), pp. 679-706.

[22] Tarver, C. M., Chidester, S. K., and Nichols III, A. L., 1996. "Critical Conditions for Impact- and Shock-Induced Hot Spots in Solid Explosives". J. Phys. Chem., 100, pp. 57945799.

[23] Fried, L. E., Howard, W. M., and Souers, P. C., 2000. Cheetah 3.0 User's Manual. Tech. rep., Lawrence Livermore National Laboratory, Livermore, CA, September. UCRLMA-117541 Rev 6.

[24] Bird, R. B., Stewart, W. E., and Lightfoot, E. N., 1960. Transport Phenomena. Wiley, New York.

[25] Gey, W. A., Dalbey, E. R., and Van Dolah, R. W., 1956. "Studies on the Linear Crystallization of TNT Systems". $J$. Amer. Chem. Soc., 78(9), pp. 1803-1810.

[26] Drimmer, B. E., 1983. Navy Bank of Explosives Data, Volume III. Tech. rep., Naval Surface Warfare Center. Report NSWC MP 83-230.

[27] Pandey, J. D., Sanguri, V., Dwivedi, D. K., and Tiwari, K. K., 2007. "Computation of isothermal compressibility, thermal expansivity and ultrasonic velocity of binary liquid mixtures using hole theory". J. Molec. Liq., 135(1), pp. 6571.

[28] Hu, H., and Argyropoulos, S. A., 1996. "Mathematical Modeling of Solidification and Melting: a Review". Modelling Simul. Mater. Sci. Eng., 4(4), pp. 371-396.

[29] Hashemi, H. T., and Sliepcevich, C. M., 1967. "A Numerical Method for Solving Two-Dimensional Problems of Heat Conduction with Phase Change". Chem. Eng. Prog. Symp. Series, 63, pp. 34-41.

[30] Voller, V. R., and Swaminathan, C. R., 1991. "General Source-based Method for Solidification Phase Change". Numer. Heat Trans., 19(2), pp. 175-189.

[31] Rolph, W. D., and Bathe, K. J., 1982. "An Efficient Algo- 
rithm for Analysis of Nonlinear Heat Transfer with Phase Changes". Int. J. Numer. Meth. Eng., 18(1), pp. 119-134.

[32] Eyres, N. R., Hartree, D. R., Ingham, J., Jackson, R., Sarjant, R. J., and Wagstaff, J. B., 1946. "The Calculation of Variable Heat Flow in Solid". Phil. Trans. R. Soc. A, 240(813), pp. 1-57.

[33] Karasevskii, A. I., and Lubashenko, V. V., 1996. "Melting as a first-order phase transition in a system of defects". Physica Status Solidi. B - Basic Research, 192(2), pp. $483-497$. 